\title{
LETTERS
}

\section{Suicides among medical trainees}

I would like to make a few additions to the interesting report by Lauren Vogel, "US doctors call for tracking suicides among medical trainees," published in CMAJ. ${ }^{1}$

In a recent systematic review by Coentre and Góis, with 13244 medical students from 13 different countries, the prevalence of suicidal ideation ranged from $7 \%$ to $35.6 \%$ within the preceding 12 months. ${ }^{2}$ The following major risk factors of suicidal ideation in medical students were identified: depression or depressive symptoms, previous diagnosis of a psychiatric disorder, perceived parental neglect, history of drug use, and lower socioeconomic status or financial difficulties. ${ }^{2}$

Researchers from the University of British Columbia estimated a suicide rate of 8.7/100000 medical students per year based on a survey of the 17 Canadian medical undergraduate programs (MDUPs); 16 schools participated. ${ }^{3}$ The authors found that less than half of responding medical schools (44\%) recorded data on student deaths, and only 10 MDUPs had an existing policy for responding to a suicide. For further preventive work in this area, including the exploration of risk and pro- tective factors, the authors consider a national reporting strategy or a longitudinal prospective study to be necessary. ${ }^{3}$

According to a recently published systematic review by Blacker and colleagues, comprehensive and reliable international data on medical student suicides are not available. ${ }^{4}$ The authors conclude that "Accurate suicide data are needed to identify trends, establish predisposing and predictive factors, and identify targets for intervention." ${ }^{4}$ To highlight the importance of comprehensive data collection on suicides among medical trainees, I recommend this review as a resource. In addition, the recent position paper by the Canadian Federation of Medical Students on responding to medical student suicide ${ }^{5}$ is worth reading.

Finally, in the first review of the international literature on suicide among physicians published nearly 50 years ago, Dr. Mathew Ross reported on possible and desirable preventive measures. ${ }^{6}$ The important influencing factors documented at that time were age, gender, medical school affiliation, type of medical practice and specialty, the state of physical and emotional health, psychiatric morbidity, the use of alcohol and drugs, and professional and psychosocial factors. ${ }^{6}$
Wouldn't a call for tracking suicides among Canadian medical trainees be desirable as well?

\section{Martin Hofmeister PhD}

Nutrition scientist, Department of Food and Nutrition, Consumer Centre of the German Federal State of Bavaria, Munich, Germany

Cite as: CMAJ 2019 May 6;191:E510. doi: 10.1503/cmaj.71916

\section{References}

1. Vogel L. US doctors call for tracking of suicides among medical trainees. CMAJ 2019;191:E26.

2. Coentre R, Góis C. Suicidal ideation in medical students: recent insights. Adv Med Educ Pract 2018;9:873-80.

3. Zivanovic R, McMillan J, Lovato C, et al. Death by suicide among Canadian medical students: a national survey-based study. Can J Psychiatry 2018;63:178-81.

4. Blacker CJ, Lewis CP, Swintak CC, et al. Medical student suicide rates: a systematic review of the historical and international literature. Acad Med 2019;94:274-80.

5. Yung E, Lagace F, Zhong YJ, et al. CFMS position paper on responding to medical student suicide. Proceedings of the 2018 CFMS Annual General Meeting; 2018 Sept. 21-23; Montréal. Ottawa: Canadian Federation of Medical Students (CFMS); 2018. Available: www.cfms.org/files/ meetings/agm-2018/resolutions/resolution4/CFMS \%20Position\%20Paper\%20on\%20Medical\%20 Student\%20Suicide.pdf (accessed 2019 Jan. 30).

6. Ross M. Suicide among physicians. Psychiatry Med 1971;2:189-98.

Competing interests: None declared. 